\title{
Osteogenesis imperfecta
}

INSERM

\section{Source}

INSERM. (1999). Orphanet: an online rare disease and orphan drug data base.

Osteogenesis imperfecta. ORPHA:666

Osteogenesis imperfecta (OI) comprises a heterogeneous group of genetic disorders characterized by increased bone fragility, low bone mass, and susceptibility to bone fractures with variable severity. 